\title{
Reificação, inteligência e medicalização: formas históricas e atuais de classificação na escola
}

\author{
Vivian Heringer Pizzinga1, https://orcid.org/0000-0003-4602-2267 \\ Henrique Romero Vasquez², https://orcid.org/0000-0002-3666-1375
}

\begin{abstract}
Resumo
O presente artigo procurou problematizar diferentes formas de categorização de sujeitos na escola, a partir de uma perspectiva histórica, cotejando a função do coeficiente de inteligência com a função da medicalização realizada através de diagnósticos psiquiátricos, processos que operam no sentido da falácia da reificação, processo através do qual abstrações estatísticas são tomadas como 'coisas reais'. Discutiu-se a acurácia do conceito de medicalização, através de um breve panorama de sua modificação conceitual ao longo do tempo. Fez-se, ademais, uma análise da entrada da psicologia na escola e dos estudos eugenistas de inteligência no início do século XX, de forma a permitir uma discussão pautada na orientação ética que alerta para o risco dos sistemas classificatórios (de inteligência ou de diagnósticos psiquiátricos), que podem induzir o engessamento da subjetividade do indivíduo. Concluiu-se que a medicalização, assim como o eugenismo, apresenta um foco no indivíduo problema e em determinantes supostamente biológicos.
\end{abstract}

Palavras-chave: Medicalização; inteligência; psicologia escolar.

\section{Reification, intelligence, and medicalization: historical and current forms of classification in school}

\begin{abstract}
This article aims to problematize different forms of categorization of subjects in the school, from a historical perspective, comparing the function of the coefficient of intelligence with the function of medicalization performed through psychiatric diagnoses, processes that operate in the sense of the reification fallacy, process through which statistical abstractions are taken as 'real things'. The accuracy of the concept of medicalization has discussed through a brief overview of its conceptual modification over time. In addition, an analysis was made of the entrance of psychology in school and of eugenics studies of intelligence in the early twentieth century, in order to allow a discussion based on the ethical orientation that alerts to the risk of classification systems (intelligence or diagnostics psychiatric disorders) that can induce the subjectivity of the individual. It has concluded that medicalization, like eugenics, presents a focus on the problem individual and on supposedly biological determinants.
\end{abstract}

Keywords: Medicalization; intelligence; school psychology.

\section{Reificación, inteligencia y medicalización: formas históricas y actuales de clasificación en la escuela}

\begin{abstract}
Resumen
En el presente artículo se buscó problematizar diferentes formas de categorización de sujetos en la escuela, a partir de una perspectiva histórica, cotejando la función del coeficiente de inteligencia con la función de la medicalización realizada por intermedio de diagnósticos psiquiátricos, procesos que operan en el sentido de la falacia de la reificación, proceso por medio de lo cual abstracciones estadísticas son tomadas como 'cosas reales'. Se discutió la exactitud del concepto de medicalización, por intermedio de un breve panorama de su modificación conceptual a lo largo del tiempo. Se hace, además, un análisis de la entrada de la psicología en la escuela y de los estudios eugenistas de inteligencia en el inicio del siglo XX, de forma a permitir una discusión basada en la orientación ética que alerta para el riesgo de los sistemas clasificatorios (de inteligencia o de diagnósticos psiquiátricos), que pueden inducir a enyesar la subjetividad del individuo. Se concluye que la medicalización, así como el eugenismo, presenta un enfoque en el individuo problema y en determinantes supuestamente biológicos.
\end{abstract}

Palabras clave: Medicalización; inteligencia; psicología escolar.

1 Universidade Estadual do Rio de Janeiro - Rio de Janeiro - RJ - Brasil.

2 Universidade Federal do Rio de Janeiro - Rio de Janeiro - RJ - Brasil.

Psicologia Escolar e Educacional, SP. Volume 22, Número 1, Janeiro/Abril de 2018: 123-131. 


\section{Introdução}

Atualmente, há um debate acirrado sobre o que se considera medicalização excessiva da vida (Illich, 1975) e, mais especificamente, a medicalização na infância. Em 2015, o Ministério da Saúde lançou um documento (Brasil, 2015) cujo intuito era frear a prescrição excessiva de medicamentos voltados para o diagnóstico controverso de TDAH (Transtorno de Déficit de Atenção e Hiperatividade), uma vez que, em 2010, o Brasil se tornou o segundo mercado mundial no consumo de metilfenidato (Torcato, 2016). A proliferação de diagnósticos tem levado a um aumento da prescrição medicamentosa em crianças muito novas, processo que levanta questões éticas prementes.

Como apontam Rocha e Cavalcanti (2014), diferente do caso dos adultos, que, em certas situações, podem ter suas experiências de sofrimento ressignificadas de modo positivo a partir de um diagnóstico psiquiátrico, no caso de crianças, o diagnóstico pode fazer com que seu destino seja precocemente marcado a partir da classificação recebida. Como aponta Bezerra Jr. (2014), o recebimento de um diagnóstico, por sua "força performativa", possui desdobramentos psíquicos e sociais que não são desprovidos de repercussão. Se hoje é o diagnóstico psiquiátrico que pode se tornar um rótulo indelével que modifica comportamentos e expectativas face ao sujeito diagnosticado, descrito a partir de um código que se refere a um transtorno psíquico, é possível dizer que, na ocasião em que a psicologia entrou na escola, a categoria de inteligência assumiu inicialmente esse papel. Era o início do século XX, e os psicólogos americanos sentiram que a psicologia experimental de Wundt não tinha aplicações práticas o suficiente: eles diziam que "precisamos de uma psicologia usável" (Hall, 1912, citado por Schultz \& Schultz, 1981, p.175) Era o momento em que o saber psicológico, na ânsia de se legitimar enquanto ciência, buscava lançar mão de medidas psicológicas que encontrassem uma aplicação prática nos contextos em que buscava se inserir.

Os efeitos derivados da identificação de um sujeito a partir de uma categoria estanque já eram uma preocupação de Alfred Binet quando elaborou sua escala de inteligência. Binet a elaborou na primeira década do século $X X$, ao ser convidado pelo governo francês para compor uma comissão visando elaborar indicadores que permitissem identificar as crianças que necessitavam de educação alternativa. Essa escala tinha como objetivo original ajudar na compreensão das situações de aprendizagem e na intervenção para sua melhoria. Longe de promover uma cristalização do conceito de inteligência, a proposta da escala era a de fornecer um instrumento para identificação de problemas e sua posterior resolução. Binet insistiu que as medidas de sua escala não indicavam a inteligência em si, algo por demais complexo para ser condensado em um único número (Gould, 1999).

Nesse sentido, procura-se aqui examinar o paralelo entre a categorização de sujeitos através de dois processos: o estabelecimento de um coeficiente de inteligência e o processo de medicalização que, nesse âmbito específico, se dá por intermédio de diagnósticos psiquiátricos algumas vezes apressados em crianças cujos comportamentos são interpretados como sintomas de transtornos específicos. Sabe-se que um diagnóstico psiquiátrico não é inócuo, da mesma maneira que um rótulo relacionado a uma medida de inteligência tampouco o é. Desse modo, será aqui discutido o paralelo da medicalização na infância propriamente dita e a entrada da psicologia na escola, com seus instrumentos de medição e diagnóstico, mas, anteriormente, a partir da consideração da advertência que aponta para o uso impreciso do termo medicalização (Zorzanelli, Ortega, \& Bezerra Jr., 2014) será traçado um panorama do conceito a partir desses autores.

\section{Discussões acerca do conceito de medicalização}

Segundo Davis (2006), o termo medicalização ganhou suas primeiras formulações a partir da década de 60 com o alargamento do campo de intervenção da psiquiatria. No entanto, segundo o autor, o conceito sofreu uma expansão inapropriada, ao desatrelar a profissão médica da definição do processo. Assim, a medicalização, tal como foi inicialmente definida por diversos autores, dizia respeito à ampliação da jurisdição médica sobre comportamentos que antes não eram tidos como problemas médicos e que, a partir de então, passam a receber tratamento médico. Barbara Wootton (1956, citado por Zorzanelli \& cols., 2014 ) já denunciava a vitória da moral em relação à medicina, na medida em que profissionais médicos passaram a opinar sobre matérias ordinárias da vida cotidiana que não Ihe diziam respeito, dentro do âmbito da psiquiatria. Freidson (1988, citado por Zorzanelli \& cols., 2014) e Zola (1972, citado por Zorzanelli \& cols., 2014) expandiram a problemática da medicalização do terreno mais estreito da psiquiatria para outras especialidades médicas, e sua crítica, segundo Davis (2006), se refere ao fato de que a suposta objetividade científica das formulações médicas face a determinados comportamentos e modos de vida acaba por ofuscar o julgamento moral que se faz deles. Os julgamentos morais são escamoteados pela suposta neutralidade do conhecimento científico. No entanto, a partir dos anos 90 , segundo a crítica de Davis (2006), essas primeiras formulações não perduraram e, com a expansão do conceito, sua definição não mais foi atrelada necessariamente à profissão médica. Ao citar Peter Conrad em sua última definição, a medicalização englobaria o processo que passa a definir comportamentos antes não-médicos como médicos, mas o desconecta da medicina, dado que outros atores sociais poderiam promover o processo (Davis, 2006).

Em artigo que traça um panorama histórico dos diferentes usos do conceito de medicalização, Zorzanelli e cols. (2014) chamam a atenção para as críticas que, a partir dos anos 2000, como a que foi formulada por Davis (2006), apontam para uma crescente imprecisão no uso do 
termo, o que resulta em perda de parte da acurácia analítica do conceito. Desse modo, a noção de medicalização vai se tornando cada vez mais vaga e sem embasamento teórico (Zorzanelli \& cols., 2014). No mesmo trabalho, os autores defendem a transitividade do conceito, isto é, que se possa especificá-lo de acordo com o contexto em que é usado, evitando o uso homogeneizante do termo.

Uma primeira demarcação importante ao analisar o surgimento e as transformações sofridas pelo termo medicalização refere-se ao contexto em que foi utilizado. As contribuições de Foucault (2010) ao tema são relevantes, contudo é importante estabelecer uma diferença entre sua teorização e a de demais autores. Assim, o processo ao qual inicialmente se refere em sua obra remete ao contexto europeu que vai do fim do século XVII ao início do século XIX e às medidas de saúde relacionadas à constituição do Estado-nação, mais especificamente àquilo que dizia respeito ao fortalecimento da força de trabalho e da população frente às outras nações (Foucault, 2010). Nesse ponto, distancia-se de autores como Peter Conrad, Ivan IIllich e outros, cujos debates referem-se a processos ocorridos no século XX, pós-Segunda Guerra (Zorzanelli \& cols., 2014). Ainda que não faça uso sistemático do termo medicalização em sua obra, Foucault (2010) faz referência ao processo na medida em que assinala a constituição de uma sociedade cuja compreensão do indivíduo e da população, além de seu manejo, será feita a partir da medicina (Gaudenzi \& Ortega, 2012).

Ivan IIllich, em Nêmesis da Medicina (1975), já indicava o que considerava como o problema da medicalização excessiva da vida. Illich (1975) apontava para a expropriação que as práticas médicas acabam por causar em relação ao saber do indivíduo sobre o seu próprio corpo e à autonomia do sujeito na maneira de lidar com a sua saúde e com características corporais e físicas de etapas da vida, que em outras épocas não eram medicalizadas e que em algumas culturas ainda não o são (Illich, 1975). O autor constrói a noção de 'imperialismo médico' ao se referir ao processo de supervisão médica de todos os aspectos da vida, identificando a medicalização como sendo o resultado do processo de industrialização (Gaudenzi \& Ortega, 2012). Em uma sociedade medicalizada, a maneira de relação do indivíduo com o sofrimento acaba por ser mediada por e depender de práticas médicas e de terapeutas profissionais. Para Illich (1975), a cultura também fornece maneiras de lidar com a dor e a integra em um sistema simbólico que, a partir da colonização médica, acaba se tornando algo que deve ser eliminado a qualquer custo através de uma parafernália médica e técnica cujo uso dependerá de especialistas. A urgência de supressão da dor é própria do que Illich chama de "sociedade dominada pela analgesia" (Illich, 1975, p. 116). A dor perde, assim, sua dimensão de experiência íntima e incomunicável para se tornar algo a ser medido e matéria de diagnóstico. Ela, neste sentido, entra em um campo de objetividade, números, limiares, parâmetros e tabelas, saindo do terreno do sentido. Nesse caso, é a profissão médica que detém o poder de decidir quais as dores podem ser consideradas autênticas e, por outro lado, quais aquelas que seriam imaginadas, simuladas e talvez não legitimadas. O autor denomina esse processo de "gestão técnica das sensações, das experiências e do porvir individuais" e de "gestão da fragilidade", expressões sugestivas para se pensar a inserção da medicalização enquanto gestão de certa fragilidade psíquica e comportamental no âmbito mais específico da saúde mental, seja aquela direcionada a adultos, seja a que se refere à infância e à adolescência.

Para Peter Conrad, em sua primeira definição, medicalização definia "um comportamento como um problema médico" e licenciava "à profissão médica a oferta de algum tipo de tratamento para tal comportamento" (Conrad, citado por Zorzanelli \& cols., 2014). O autor, porém, se debruçou sobre os processos de medicalização desde os anos 70 e pôde reformular as definições que teceu a partir de mudanças que observou em relação a certos diagnósticos e sua proliferação. Em sua reformulação, a medicalização seria o "processo em que problemas não-médicos se tornaram definidos e tratados como problemas médicos, comumente em termos de doença e transtornos" (Conrad, 2007, p. 4). Assim, para o autor, que observa que o número de condições que vêm sendo definidas como médicas têm crescido enormemente, a chave do conceito reside na definição do problema, isto é: se ele é definido em termos e em linguagem médica, compreendido a partir da adoção do arcabouço médico e a solução para ele (se pede uma solução) é dada através da intervenção médica, tem-se aí um processo de medicalização. Todavia, Conrad discorda de Ivan Illich (1975) quando este último usa o termo "imperialismo médico" para definir o que ocorre, dizendo que o processo de medicalização é mais complexo do que a "anexação de novos territórios pelos médicos e pela profissão médica” (Conrad, 2007, p. 5). Em sua definição mais tardia, medicalização não se restringe à profissão médica e haveria níveis diferentes de medicalização, em que algumas condições são mais intensamente medicalizadas, como a morte, o nascimento e a doença mental, outras são parcialmente medicalizadas, como a menopausa, e outras são levemente medicalizadas, como a ninfomania.

Ao estudar os processos medicalizantes, Conrad (2007) é claro em assinalar que seu interesse não é a discussão sobre se dadas condições tidas como médicas são ou não são de fato condições médicas, isto é, o autor não está interessado em fazer uma ontologia nosológica. Seu objetivo é levantar e compreender os alicerces sociais da expansão da jurisdição médica, além de entender as implicações sociais desse processo. O autor aponta, inicialmente, que o processo que transforma alguns problemas naturais da vida em categorias nosológicas tem como consequência o estreitamento do campo do que é considerado aceitável. Ademais, o foco recai no indivíduo, ou seja, é no nível das intervenções individuais que as soluções serão propostas, em vez de um olhar que procure compreender o ambiente social e que busque soluções coletivas. Conrad (2007) também afirma que a ampliação da jurisdição médica em relação aos problemas ordinários da vida produz o consequente aumento do controle social do comportamento humano. É 
possível perceber que a medicalização traz uma série de desdobramentos problemáticos no que tange à compreensão e à solução de problemas.

Assim, quando pensamos em uma das questões assinaladas pelos estudiosos e críticos da medicalização excessiva da vida, entre os quais Conrad (2007), e que diz respeito à individualização de problemas que são coletivos, não se pode deixar de problematizar a medicalização da infância, sobretudo no âmbito escolar, como uma vertente de tal processo, uma vez que ao encontrar diagnósticos diversos (déficit de atenção, transtorno bipolar, transtorno de ansiedade, fobia social, espectro autista, entre muitos outros) para dar conta de dificuldades que podem dizer respeito ao contexto mais amplo da escola, da família e da comunidade, deixa-se de empregar esforços outros que se dirijam às dificuldades macrossociais. Por outro lado, a psicologia fez sua entrada no cenário escolar trazendo para ele sua versão clínica, atuando segundo o modelo médico, cujo viés buscava solucionar problemas de aprendizagem e adaptação de modo sempre individual, lançando mão de categorias que eram consideradas como sendo passíveis de mensuração. Ainda que não se tratasse de uma medicalização propriamente dita, é possível detectar semelhanças na lógica individualizante que subjaz a tais práticas.

\section{Entrada da psicologia aplicada}

\section{na escola}

A entrada da psicologia na escola é muito anterior à psicologia escolar propriamente dita. Wundt ${ }^{2}$ é, frequentemente, considerado um pioneiro na psicologia científica, tendo sido o fundador do primeiro laboratório de psicologia, com o objetivo de estudar a estrutura dos processos mentais. Na primeira parte de sua obra, Wundt se dedicou predominantemente à psicofisiologia da percepção, estudando a percepção dos estímulos externos através de experimentos com introspecção. Depois, escreveu sobre a psicologia dos povos, que planejava descrever como o contexto cultural influencia os processos mentais. Se assumirmos como ponto inicial da psicologia científica a psicologia de Wundt, então o mais provável candidato para a primeira entrada da psicologia na escola é o funcionalismo americano do final do século XIX e início do século XX. Segundo Schultz e Schultz (1981), os psicólogos americanos que foram estudar no laboratório de Wundt, em Leipzig, se afastaram de seu sistema teórico ao voltar para a América.

Araújo (2005) relata que a obra wundtiana é mal interpretada nos livros textos de história da psicologia; identifica-se, muitas vezes, a psicologia de Wundt com o estruturalismo elementarista de Titchener. Para o autor, todavia, essas duas psicologias apresentam diferenças importantes.

2 Wilhelm Wundt, nascido em 16 de agosto de 1832 e falecido em 31 de agosto de 1920, foi o criador do primeiro laboratório de psicologia. Sendo assim, muitos historiadores o consideram o fundador da psicologia científica (Araújo, 2005)
Entre elas, a que mais nos interessa destacar é a Völkerpsychologie (psicologia dos povos) de Wundt, descartada completamente nos modelos psicológicos de Titchener $^{3}$, que argumentava que a única forma da psicologia permanecer científica seria se ater rigorosamente à psicofisiologia. A psicologia dos povos mostra uma preocupação com fenômenos coletivos já naquele momento. Porém, isso não traslada para o estruturalismo de Titchener (Op. cit.), e menos ainda para a psicologia americana (Schultz \& Schultz, 1981):

"Precisamos de uma psicologia usável", escreveu G. Stanley Hall, o decano da psicologia aplicada americana. "Os pensamentos wundtianos nunca poderão se aclimatar aqui, pois são antipáticos ao espírito e ao temperamento americanos" (Hall, 1912, p. 414). Os psicólogos americanos recém-treinados retornaram da Alemanha e, à maneira tipicamente direta e agressiva da América, transformaram a espécie peculiarmente germânica de psicologia. Começaram a estudar não o que a mente é, mas o que faz (pp. 173 - 174).

Apesar de boa parte dos psicólogos americanos terem estudado psicologia nos laboratórios de Leipzig, eles queriam uma psicologia que não fosse uma disciplina exclusivamente acadêmica. Ao contrário, pretendiam justificar essa nova disciplina justamente por sua serventia para a sociedade. Havia também uma preocupação com a popularização da psicologia, com os novos PhDs participando de demonstrações abertas ao grande público. Essa nova espécie de psicologia aplicada americana tentava solucionar problemas presentes no cotidiano, o que incluía o contexto escolar.

Na verdade, é possível dizer que a escola pública foi o principal front da psicologia aplicada:

\begin{abstract}
A solução, portanto, era evidente: tornar a psicologia mais valiosa mediante sua aplicação. Mas aplicá-la a quê? Felizmente, a resposta logo se tornou clara: as matrículas nas escolas públicas sofriam um crescimento dramático; entre 1870 e 1915, o número de alunos matriculados elevouse de sete para vinte milhões... Perto de 1910, mais de um terço dos psicólogos americanos se mostravam interessados pela aplicação da disciplina a problemas educacionais. Três quartos dos que se intitulavam psicólogos aplicados já trabalhavam na área. A psicologia encontrara o seu lugar no mundo real. (Schultz \& Schultz, 1981, p.176).
\end{abstract}

No entanto, no que diz respeito à abordagem das problemáticas sociais, o foco individualizante será, conforme veremos ao longo do texto, prevalente.

Granville Stanley Hall, nascido $1^{\circ}$ de fevereiro de 1846, falecido 24 de abril de 1924, foi um dos primeiros psicólogos desenvolvimentistas e esteve entre os maiores expoentes do movimento da psicologia aplicada. Assim

3 Edward Titchener, nascido em 11 de janeiro de 1867 e falecido 3 de agosto 1927, foi um dos mais conhecidos alunos do laboratório de Wundt e um dos principais precursores da psicologia estruturalista. (Araújo, 2005) 
como boa parte de seus contemporâneos, ele foi bastante influenciado por Darwin, sendo o pioneiro na aplicação da teoria da recapitulação ao desenvolvimento psicológico (Schultz \& Schultz, 1981). Basicamente, a teoria dizia que, ao longo do desenvolvimento psíquico, as crianças recapitulam toda a história evolutiva da raça humana. Schultz e Schultz dão o exemplo da brincadeira de caubóis e índios, que supostamente replicava o modo de agir de povos primitivos. Hall ficou conhecido por seus grandes e compreensivos manuais de psicologia aplicada à educação de crianças e adolescentes, como seu "Youth: Its Education, Regimen, and Hygiene" (Hall, 2005), que consta dos métodos corretos de criar e educar meninos e meninas para que ocupem seu devido lugar na sociedade. A associação entre desenvolvimento e evolução, bem como a noção de um percurso normal de desenvolvimento, pode ter preparado o solo para que, anos depois, surgissem as teorias eugenistas de $\mathrm{H}$. $\mathrm{H}$. Goddard, discutidas por Gould (1999), que serão abordadas mais adiante.

Witmer (nascido 28 de junho de 1867, falecido 19 de julho de 1956), autor que também se insere no paradigma psicológico aqui discutido, foi um dos primeiros a se debruçar sobre o então chamado 'comportamento anormal'. Estudou brevemente com Cattel ${ }^{4}$, depois com Wundt e, após se desiludir com os métodos de pesquisa wundtianos, ele desenvolveu um novo método de trabalho: a psicologia clínica. Witmer foi o primeiro psicólogo a utilizar o conceito de clínica psicológica, mas com uma definição bem diferente da que hoje conhecemos, pois se detinha na avaliação e correção de problemas de aprendizagem (Schultz \& Schultz, 1981).

Começamos a observar, então, como a psicologia pode ter configurado a educação como um campo propício para apropriação pelas ciências da saúde. Desde o início de sua história, a psicologia entra na escola (ou, pelo menos, tira o aluno da escola), numa tentativa de normatizar o desempenho escolar através de modelos biomédicos, como a recapitulação de Hall ou a intervenção clínica de Witmer. Essa lógica, cujo foco recai sobre o 'aluno-problema', parece conter elementos similares àqueles presentes nas situações atuais de medicalização da educação.

A questão da individualização do problema que aparece para a psicologia ou para outros modelos clínicos (como o modelo médico) aparece, ainda nos primórdios da psicologia aplicada, de um modo enviesado em que os conceitos psicológicos usados inicialmente como ferramenta para a melhora da aprendizagem ou para o mapeamento dos problemas e sua posterior solução, acabaram por ser deturpados, como é o caso do conceito de inteligência. A reificação equivocada de tal conceito levou a perigosas definições estigmatizantes sem nenhuma consideração crítica acerca do contexto social e cultural que poderia ter importância nos próprios achados dos testes e suas posteriores classificações. A reificação, segundo Gould (1999, p. 159)

\footnotetext{
4 Raymond Cattell, nascido em 20 de março de 1905 e falecido em 2 de fevereiro de 1998, foi um importante psicometrista ativo tanto na Grã-Bretanha quanto nos Estados Unidos. Era especialmente interessado em medidas de personalidade. (Schultz \& Schultz, 1981)
}

constitui-se em uma falácia que consiste na "suposição de que os resultados obtidos nos testes correspondem a uma entidade independente, uma magnitude escalonada, situada na cabeça e denominada inteligência geral". Neste sentido, pode-se apontar um paralelo entre a classificação rígida dos indivíduos de acordo com o nível de inteligência em que se situavam, a partir de testes cujos pressupostos epistemológicos podem ser questionados, e a classificação diagnóstica própria da medicalização, que muitas vezes desconsidera o ambiente em que se insere aquele que recebe o diagnóstico. Ambos, ao entrar no âmbito escolar de modo acrítico, suscitam questões éticas que devem ser discutidas. Aqui, a classificação, seja pelo coeficiente de inteligência, seja pelo diagnóstico psiquiátrico, deve ser problematizada em relação às consequências clínicas e sociais para o sujeito submetido a tais sistemas classificatórios, sempre arbitrários.

\section{O eugenismo americano e a reificação da inteligência}

Com a visibilidade que a teoria da evolução adquiriu no início do século XX, tentou-se aplicá-la aos seres humanos, especulando quais características tornariam a espécie humana mais adaptada, e como elas poderiam ser cultivadas em uma população. Aquilo que era então tratado como inovação científica é o que hoje sabemos ser uma noção extremamente problemática: a de que alguns seres humanos são melhores do que outros. Essa linha de pensamento, que ainda hoje vem à tona, chama-se eugenia. No início do século $X X$, a eugenia era muito relacionada com a medição da inteligência (Gould, 1999), porém em sua origem a medição da inteligência não era de forma nenhuma um esforço eugenista, ela apenas foi apropriada pelos eugenistas como forma de validar suas posições.

A medição psicométrica da inteligência teve início com a obra do psicólogo francês Alfred Binet (Gould, 1999). Ao se desiludir com a craniometria ${ }^{5}$ como forma de observar a inteligência humana, Binet desenvolveu um modo de testagem que envolvia a realização de diferentes tarefas pela criança. Com seu novo método de medida, abandonou não só as propostas metodológicas da craniometria, mas também seus pressupostos básicos: Binet não considerava a inteligência algo determinado somente por variações biológicas, ou algo hereditário, nem, menos ainda, reificava o conceito, como se fosse estanque e desprovido de complexidade. Nesse sentido, sua escala fora elaborada para ser aplicada aos alunos com maior dificuldade, de forma a se perceber em quais tarefas específicas residiam seus maiores desafios e, a partir desses achados, tentar pensar em soluções que não apenas diminuíssem a discrepância entre os alunos como também facilitassem a aprendizagem daqueles com maior dificuldade, levando-se em considera-

5 A craniometria era uma disciplina da antropologia física que propunha a medição da inteligência pela medição do tamanho da caixa craniana. (Gould, 1999) 
ção o papel da educação criativa e o papel do meio. Seu objetivo não era a cristalização, portanto, do coeficiente da inteligência, como acabou acontecendo posteriormente com as traduções de seus testes e seu uso irrestrito e acrítico. Binet usava o termo 'ortopedia mental' para conceituar esses procedimentos. Apesar de se tratar de um termo que pode suscitar repúdio ou suspeita, é importante entender a tentativa do autor em buscar soluções pragmáticas e levar em conta sua consciência crítica face ao perigo das classificações daquilo que, posteriormente, veio a ser chamado como 'profecia autorrealizada'. ${ }^{6}$ Ainda assim, é importante assinalar que Binet, apesar de suas preocupações e problematizações éticas, continuava centrando os problemas de aprendizagem no nível individual.

Quando o teste de Binet chegou à América, toda a parte teórica de sua obra sobre a definição da inteligência ficou para trás. Os psicólogos hereditaristas americanos, que talvez tenham sido os primeiros psicometristas da América, se apropriaram de suas metodologias de medição. Mas, diferente de Binet, eles acreditavam que o que estava sendo medido era a inteligência inata. H. H. Goddard ${ }^{7}$, por exemplo, acreditava que a debilidade mental era determinada por um único gene recessivo, que estava presente em muito maior frequência nos pobres, negros, latinos e imigrantes de modo geral. De tal forma, não adiantava educá-los em conjunto com os demais, pois isso não solucionaria o problema. Segundo Goddard, a única solução possível era a internação e o controle reprodutivo dos que eram classificados como débeis mentais ${ }^{8}$.

Goddard, ao assumir a hereditariedade da inteligência, retirava a questão do âmbito da educação, ao desconsiderar qualquer possibilidade de o meio ter influência sobre essa característica. A inteligência baixa passava a ser, por conseguinte, uma sentença inescapável, e o conceito de debilidade mental, por ele desenvolvido, carregava um cunho patologizante, trazendo uma cegueira face aos aspectos sociais que poderiam afetar o desempenho dos sujeitos nas tarefas propostas durante as testagens. Juntava-se a isso o fato de que o método de diagnóstico de Goddard era, segundo Gould (1999), claramente deficiente do ponto de vista epistemológico. Goddard, após algum tempo, chegou a abandonar qualquer forma mais rigorosa de testagem psicométrica, empregando pesquisadoras que supostamente conseguiam, exatamente por serem mulheres, reconhecer a debilidade mental através de uma simples e breve ob-

6 Nas palavras de Gould (1999, pp. 154-155): "Mas o que mais ele [Alfred Binet] temia era a 'previsão que garante a própria realização'. Um rótulo rígido pode condicionar a atitude do professor e, a longo prazo, desviar o comportamento da criança para o caminho previsto".

7 Henry Goddard, nascido 14 de agosto de 1866 e falecido 18 de junho de1957, foi um psicólogo e eugenista americano, que elaborou o conceito clínico de débil mental (Gould, 1999).

8 Para Goddard, conforme citado por Gould, havia três tipos de deficientes mentais: os idiotas, cuja idade mental variava de 0-3 anos; os imbecis, cuja idade mental variava de 3-6 anos; e, finalmente, os débeis mentais, cuja idade mental variava entre 6-12 anos e que, apesar de ser um nível mais brando de deficiência, era o mais difícil de detectar e, portanto, o que mais ameaçava os interesses eugenistas. servação de certas características físicas. Os critérios para efetuar esse reconhecimento eram obscuros e, nesse caso, contavam com a categoria gênero, sem que houvesse, menos ainda, uma elaboração conceitual de tal categoria. O resultado foi um aumento significativo na tendência à classificação da categoria de débeis mentais.

Lewis M. Terman ${ }^{9}$, por sua vez, introduziu a testagem de QI em grande escala no âmbito escolar nos Estados Unidos, avançando e tornando mais complexas as propostas de Goddard. Sua escala de Stanford-Binet era muito mais completa e padronizada do que a escala original, e podia ser aplicada por qualquer pessoa em um grande número de sujeitos. Terman defendia que toda criança, sem exceção, fosse testada. Vale lembrar que esse objetivo já se constitui em uma deturpação da proposta original de Alfred Binet, que visava apenas os alunos que apresentassem algum problema de aprendizagem. Mas, além disso, o objetivo proposto por Terman acabava por levar a falácia da reificação às suas últimas consequências, ao se propor um constructo de inteligência inata e hereditária: as crianças que obtivessem resultados piores no teste seriam incapazes de superar suas dificuldades em qualquer grau significativo. A questão ética implícita é a de que seus testes e as conclusões a que chegou a partir de sua aplicação levavam a um paroxismo eugenista, como se constata quando Terman defende que todos os deficientes mentais eram "no mínimo, criminosos em potencial. É praticamente indiscutível que toda mulher que sofre de deficiência mental é uma prostituta em potencial." (conforme citado por Gould, 1999, p.187).

Os adeptos da teoria da hereditariedade obtiveram algum sucesso com suas propostas, pois o paradigma jingoísta, caracterizado por um ufanismo exacerbado vigente no período do entreguerras, provou-se um ambiente propício para elas. Em 1924, as leis de imigração realmente foram modificadas para ficarem mais rígidas, e um dos grupos a pressionar o congresso para essa alteração foi justamente o destes cientistas. Seria um erro, porém, supor que a hereditariedade da inteligência era a única opinião vigente na época, pois havia críticas oriundas de diversos setores acadêmicos. O jornalista Walter Lippman, por exemplo, criticava as implicações que a teoria de Terman teria na educação pública (Gould, 1999).

A maioria destes cientistas veio a se retratar quando a onda de ultranacionalista passou, e depois da exposição dos pormenores da política nazista e dos julgamentos dos crimes de guerra, poucos entre os estudiosos e pesquisadores continuaram a argumentar pela segregação racial e pela superioridade da inteligência da raça branca. No entanto, a ideia de que a inteligência é hereditária permanece.

\footnotetext{
9 Lewis Terman, nascido em 15 de janeiro de 1877 e falecido em 21 de dezembro de 1956, foi um precursor da psicologia educacional e da testagem de QI. Foi o elaborador do teste de Stanford-Binet. (Gould, 1999)
} 


\section{Paralelos entre as medições}

\section{da psicologia escolar e os}

diagnósticos psiquiátricos no

\section{Brasil}

O desenvolvimento da psicologia, no final do século XIX e início do século XX, nos Estados Unidos, estava, como se pode ver, fortemente ligado ao desenvolvimento de medidas que situassem o saber psicológico dentro de um parâmetro científico aceitável. A categoria de inteligência se tornou um emblema desse processo, trazendo diversas consequências para a escola. Patto (2010) identifica uma continuidade entre as teorias eugenistas e as explicações biológicas do fracasso escolar:

A história das explicações do chamado "fracasso escolar" das crianças das classes populares é feita de uma sequência de ideias que, em linhas gerais, pode ser assim resumida: na virada do século, explicações de cunho racista e médico; a partir dos anos trinta, até meados dos anos setenta, as explicações de natureza biopsicológica... (p. 282).

Correia (2016), interessado no estudo da demanda de queixa escolar e em um diálogo intersetorial entre educação e saúde para fazer face a tal problemática, aponta o caráter medicalizante das intervenções clínicas no SUS, baseadas no modelo estadunidense, em que se ofusca "a história clínica, semiológica e emocional da criança e pais envolvidos nas demandas de queixa escolar" (Correia, 2016, p. 53) em prol de diagnósticos baseados em evidências.

No que tange à psicologia escolar, mais especificamente no contexto brasileiro, havia forte influência das práticas psicológicas realizadas nos Estados Unidos e também na França (Barbosa \& Marinho-Araújo, 2010). Os instrumentos psicológicos de classificação de indivíduos passaram a ser usados massivamente no interior da escola e, no Brasil, "evidenciou-se o caráter clínico e terapêutico das intervenções realizadas (Barbosa \& Marinho-Araújo, 2010, p. 394). A concepção classificatória e clínica da psicologia (trazendo para o âmbito escolar o modelo clínico da prática médica, que inclui atendimentos individuais e realização de diagnósticos) constituiu-se como abordagem predominante para tratar problemas de aprendizagem, que eram considerados a partir de uma visão que focava o aluno, excluindo seu contexto e as relações estabelecidas em sala de aula, bem como as práticas pedagógicas. Como aponta Andrada (2005), esse paradigma levou à utilização, pelo profissional de psicologia, de testes e laudos psicológicos que tentavam conferir explicações objetivas e totalizantes ao fracasso escolar, buscando causas isoladas e construindo compreensões lineares que tinham como consequência a exclusão do aluno de sala de aula. Na psicologia escolar realizada na primeira metade do século $\mathrm{XX}$, no contexto brasileiro, prevalecia: o caráter remediativo com o qual se tratavam os problemas de desenvolvimento e aprendizagem. Esse fato evidencia a forte influência da medicina e a consolidação de uma atuação clínica no trabalho do psicólogo escolar junto aos contextos educacionais, nos quais se privilegiava o enfoque psicométrico (Barbosa \& Marinho-Araújo, 2010, p. 395).

Todavia, como assinalam Barbosa e Marinho-Araújo, havia outras visões não-hegemônicas que, paralelamente, se fizeram presentes, buscando a compreensão das relações entre indivíduo e meio social.

Seguindo a preocupação norte-americana dos estudiosos em psicometria que ampliaram as escalas de Binet, no Brasil a prática da psicologia também buscou se centrar "na tarefa de construir métodos e testes capazes de classificar os indivíduos em idade escolar e pré-escolar, visando à mensuração das capacidades produtivas" (Scalcon, conforme citado por Tonus, 2013). Esse propósito acaba por oferecer justificativas tanto para divisão social, quanto para o fracasso escolar, centrando sua compreensão unicamente em causas biológicas, genéticas ou, em outras palavras, individuais.

A presença dos diagnósticos e os encaminhamentos para serviços especializados eram ferramentas frequentes na atuação do psicólogo no cenário escolar. As testagens psicológicas, no contexto educacional, coadunavam-se com os objetivos de modernização da sociedade brasileira, sobretudo ao conferir categorizações que situavam "o homem certo no lugar certo" (Bock, 1999, p.319). Trata-se, portanto, de uma forma de classificação que incorre na falácia, já apontada por Gould (1999), da reificação, que, ao buscar apreender um fenômeno complexo, desconsidera variáveis importantes para sua compreensão. Um número que indicasse a inteligência de um sujeito destinaria um lugar fixo para ele, e tal abordagem incorre em risco semelhante quando se trata de conferir diagnósticos.

Nos anos 70, a psicologia foi cada vez mais chamada para tentar solucionar os problemas de aprendizagem que apareciam na escola, mas as intervenções baseadas no arcabouço psicométrico e clínico não ajudaram a solucionar as dificuldades que apareciam. Foram atuações que "contribuíram para a passividade dos agentes escolares, uma vez que a ideia de melhora era associava ao poder de cura delegado à medicina e à psicologia" (Campos \& Jucá, 2006; Maluf, 2001, citados por Barbosa \& Marinho-Araújo, 2010). Aqui, a medicalização, como conceito que descreve um processo para além da profissão médica, abarcava os profissionais da psicologia que tentavam se firmar como profissionais ligados a uma disciplina científica. No entanto, esse contexto vem mudando, com a transformação paulatina da concepção do que consiste a prática do psicólogo escolar e dos problemas escolares, cada vez menos centrados em causas individuais.

Mas, apesar de já não se perceber um movimento tão forte em relação à medição de categorias específicas, como a inteligência, hoje os diagnósticos psiquiátricos parecem querer tomar o lugar do coeficiente de inteligência. Esse último tinha o aparato científico e positivista que Ihe conferia 
legitimidade, e distorções de sua aplicação resvalaram para concepções eugenistas perigosas. O papel de tal categoria não possui a força de antes, mas, em seu lugar, categorias diagnósticas diversas constituem a nova roupagem de antigas classificações, servindo para apaziguar as inquietações que surgem a partir de dificuldades de aprendizagem e relacionamento no âmbito da escola. É importante advertir que, diferente da categoria de inteligência, a medicalização da vida não cai no erro eugenista do início do século $X X$ de supor que haveria uma ordem de seres humanos superiores a ser preservada, e outra ordem inferior, a ser eliminada ou excluída. Mas, por outro lado, conferir um diagnóstico pode incidir na mesma falácia de reificação sobre a qual Gould já alertava ao falar das medidas de inteligência: o diagnóstico aparece como um problema individual, de origem biológica e genética, como se não houvesse influência do meio e como se o meio não pudesse modificar seus desdobramentos. A origem de um problema escolar ou de comportamento ganha sua explicação em uma abordagem médica e, nesse sentido, configurando uma doença, aponta para uma solução que será individual, novamente desconsiderando o coletivo em que o sujeito se insere. Assim, a "previsão que garante a própria realização", temida por Binet ao desenvolver suas escalas, e o receio quanto ao rótulo que se torna indelével, engessando formas de relacionamento com aquele que o recebe, surge novamente com nova apresentação: um número referente ao Código Internacional das Doenças (CID).

\section{Considerações Finais}

Ao traçar um paralelo entre as categorizações realizadas através do coeficiente de inteligência e a medicalização da infância por meio de diagnósticos psiquiátricos, o artigo discutiu a problemática referente às consequências de qualquer tipo de sistema classificatório. Se não se considera que tais sistemas possuem limitações e seus critérios são arbitrários e inacabados, porque sempre em processo de construção, corre-se o risco de promover uma leitura reducionista do sujeito, através de uma definição que se pauta por um mero número que indique sua inteligência ou por um código referente a uma condição médica, como se tais medidas não possuíssem uma relação dinâmica com o contexto em que se inserem. Tais categorias podem ser úteis, enquanto ferramentas provisórias e culturais, com a prudência de evitar o movimento de tomá-las como fins em si mesmas. Além disso, podem reduzir fenômenos complexos a explicações monocausais e deterministas. Ademais, conferir um diagnóstico possui 'força perfomativa', trazendo, no cerne desse processo, desdobramentos psíquicos e sociais.

Os estudos do início do século sobre inteligência e as práticas diagnósticas atuais podem cair na falácia da reificação mencionada anteriormente. De tal modo, conceitos que são abstrações estatísticas passam a ser tomados como "coisas reais", localizadas no cérebro do sujeito. Essa forma de pensamento limita as possibilidades de intervenção, cristalizando a subjetividade de quem é classificado, tornando a categoria na qual o sujeito é encaixado uma sentença sem escapatória. Profissionais de educação diversos, como professores, pedagogos, assistentes sociais, psicólogos, bem como aqueles que recebem encaminhamentos oriundos de escolas, devem estar atentos a esses diagnósticos médicos, no intuito de abordá-los com pensamento crítico, não deixando de levar em conta o contexto no qual as dificuldades surgem e as possíveis (e prováveis) variáveis não médicas envolvidas naquilo que é definido como problema médico. Evita-se assim, o uso desnecessário e apressado de medicamentos, cujos efeitos colaterais ainda são incertos a longo prazo.

Sendo assim, observa-se que há, com a crescente medicalização dos problemas educacionais, um foco no indivíduo enquanto problema, bem como um foco nos aspectos biológicos, o que constitui uma semelhança com os projetos eugênicos do início do século. Reforçamos novamente que não se pretende, aqui, equiparar a medicalização contemporânea com o eugenismo em termos das implicações éticas. Entretanto, pensamos que a melhor maneira de superar o foco no indivíduo enquanto causa do suposto fracasso escolar é trazer sempre que possível à tona as relações socio-políticas no contexto escolar.

\section{Referências}

Andrada, E.G.C. (2005). Novos paradigmas na prática do psicólogo escolar. Psicologia: Reflexão e Crítica, 18(2), 196-199.

Araújo, S.F. (2005). Wilhelm Wundt e o estudo da experiência interna. In: Jacó-Vilela, A.M.; Ferreira, A.A.L.; Portugal, F.T. (Orgs.), História da Psicologia: Rumos e Percursos. (pp. 93 - 104) Rio de Janeiro: Nau.

Bezerra Jr, B. (2014). A psiquiatria contemporânea e seus desafios. In: Zorzanelli, R.; Bezerra Jr, B.; Costa, J.F. (Orgs.), A criação de diagnósticos na psiquiatria contemporânea. Rio de Janeiro: Garamond, pp. 9-31.

Bock, A. (1999). A Psicologia a caminho do novo século: identidade profissional e campo social. Estudos de Psicologia, 4(2), 315-329. Recuperado: 12 maio 2016. Disponível: http:www.scielo.br/epsic.

Brasil. Ministério da Saúde. (2015). Recomendações do Ministério da Saúde para adoção de práticas não medicalizantes e para publicação de protocolos municipais e estaduais de dispensação de metilfenidato para prevenir a excessiva medicalização de crianças e adolescentes. Brasil: Ministério da Saúde.

Conrad, P. (2007). The medicalization of society: on the transformation of human conditions in treatable disorders. Baltimore: The John Hopkins University Press.

Correia, M.V.G. (2016). Diálogo intersetorial educação-saúde no atendimento público municipal à demanda da queixa escolar: Um estudo de caso no município de São Paulo. (Tese de Doutorado). IPUSP: São Paulo. 
Davis, J.E. (2006). How medicalization Lost its way. Society, 43(6), 51-56.

Foucault, M. (2010) Crise da medicina ou crise da antimedicina (Conde, H. Trad.). Verve, 18, 167-194

Gaudenzi, P.; Ortega, F. (2012). O estatuto da medicalização e as interpretações de Ivan Illich e Michel Foucault como ferramentas conceituais para o estudo da desmedicalização Interface Comunicação, Saúde, Educação, 16(40), 21-34.

Gould, S.J. (1999). A Falsa Medida do Homem (2a ed.). São Paulo: Martins Fontes.

Hall, G.S. (2005). Youth: Its Education, Regimen, and Hygiene [E-book version]. Recuperado: 15 abr. 2016. Disponível: http:// www.gutenberg.org/ebooks/9173 Acessado: 15 abr 2016

Illich, I. (1975). A expropriação da saúde: nêmesis da medicina. Rio de Janeiro: Nova Fronteira.

Barbosa, R. M., \& Marinho-Araújo, C. M. (2010). Psicologia escolar no Brasil: considerações e reflexões históricas. Estudos de Psicologia (Campinas), 27(3), 393-402.
Patto, M.H.S. (2010). A família pobre e a escola pública: anotações sobre um desencontro. In: Patto, M.H.S. (Org.), Introdução à psicologia escolar (4a ed., pp. 281-296). São Paulo: Casa do Psicólogo.

Rocha, A.M.; Cavalcanti, A.E. (2014). Riscos e limites do uso do diagnóstico psiquiátrico na infância. In: A criação de diagnósticos na psiquiatria contemporânea. Rio de Janeiro: Garamond, pp. 233252.

Schultz, D.P.; Schultz, S.E. (1981). História da Psicologia Moderna (7a ed.). São Paulo: Cultrix.

Tonus, K.P. (2013). Psicologia e Educação: repercussões no trabalho educativo. Psicologia Escolar e Educacional, 17(2), 271-277.

Torcato, C.E. (2016) O metilfenidato, a escola e a cultura farmacológica contemporânea. Revista Teias, 17(45), 83-97.

Zorzanelli, R.T.; Ortega, F.; Bezerra Jr, B. (2014) Um panorama sobre as variações em torno do conceito de medicalização entre 19502010. Ciência \& Saúde Coletiva, 19(6). Rio de Janeiro.

Recebido em: 30/11/2016 Aprovado em: 26/11/2017

http://dx.doi.org/10.1590/2175-3539201802002

\section{Errata}

No artigo "Reificação, inteligência e medicalização: formas históricas e atuais de classificação na escola", com número de DOI:

http://dx.doi.org/10.1590/2175-35392018012840, publicado no periódico Psicologia Escolar e Educacional \{online\}, 2018, vol.22, n.1: pp.123-131, na página 123:

Onde se lia: "Henrique Romero Vasquez - Universidade Estadual do Rio de Janeiro"

Leia-se: "Henrique Romero Vasquez - Universidade Federal do Rio de Janeiro"

\section{Sobre os autores}

Vivian Heringer Pizzinga - (vivianhp@globo.com)

Psicóloga do CEFET/RJ, Especialista em Terapia de Família (IPUB/UFRJ), Mestrado em Saúde Coletiva (IMS/UERJ) e doutoranda de Saúde Coletiva (IMS/UERJ). Universidade Estadual do Rio de Janeiro. Rio de Janeiro- RJ.

https://orcid.org/0000-0003-4602-2267

Henrique Romero Vasquez (hrvasquez1989@gmail.com)

Psicólogo do CEFET/RJ, Especialista em psicologia clínica pelo Instituto AVM e mestrando no PPGP - UFRJ. Universidade Federal do Rio de Janeiro. Rio de Janeiro- RJ.

https://orcid.org/0000-0002-3666-1375 unrestricted use, distribution and reproduction in any medium, provided the original article is properly cited. 
